Journal of Strategic Security

Volume 7

Number 2 Volume 7, No. 2, Special Issue

Summer 2014: The Global SOF Network

Article 5

\title{
Enabling Local Solutions to Global Problems: The Role of Cultural Intelligence in Building Global SOF Networks
}

Emily Spencer

Royal Military College of Canada, emily.spencer@forces.gc.ca

Follow this and additional works at: https://digitalcommons.usf.edu/jss

pp. 29-36

\section{Recommended Citation}

Spencer, Emily. "Enabling Local Solutions to Global Problems: The Role of Cultural Intelligence in Building Global SOF Networks." Journal of Strategic Security 7, no. 2 (2014) : 29-36.

DOI: http://dx.doi.org/10.5038/1944-0472.7.2.4

Available at: https://digitalcommons.usf.edu/jss/vol7/iss2/5

This Article is brought to you for free and open access by the Open Access Journals at Digital Commons @ University of South Florida. It has been accepted for inclusion in Journal of Strategic Security by an authorized editor of Digital Commons @ University of South Florida. For more information, please contact digitalcommons@usf.edu. 


\title{
Enabling Local Solutions to Global Problems: The Role of Cultural Intelligence in Building Global SOF Networks
}

\begin{abstract}
In order to provide regional solutions to potentially world-wide problems, global special operations forces (SOF) networks maximize the benefits of SOF, in particular, their aptitude and ability to perform in a culturally intelligent manner. Indeed, to be able to facilitate regional solutions to potentially global problems, SOF need to exhibit high levels of cultural intelligence, which requires an understanding of culture combined with an ability to apply strategic thinking. By being able to address issues critically and creatively - the hallmarks of strategic thinking - while understanding and behaving appropriately in a variety of cultural contexts, SOF, acting within global networks, provide collective, cost effective, preemptive solutions for an increasingly volatile and interconnected world. This article explores methods for increasing levels of cultural intelligence and highlights the benefits of doing so while also warning of the pitfalls of not behaving in a culturally intelligent manner.
\end{abstract}

This article is available in Journal of Strategic Security: https://digitalcommons.usf.edu/jss/vol7/iss2/5 


\section{Introduction}

Following more than a decade of war in Iraq and Afghanistan, many Western nations and their allies are tired of conflict and understandably reluctant to commit national blood and treasure in foreign lands. There is a growing lack of national will everywhere for military engagements, which is underscored by a lack of resources, both human and financial. Nonetheless, and possibly even feeding on this state of affairs, no nation is immune to the dangers that still exist. Geographic and geopolitical boundaries are increasingly less important to antagonists, as witnessed by the rise in transnational acts of aggression including terrorism, criminal activity and cyber-attacks. Nonetheless, the response to these acts of belligerence is often slowed-if not impeded-by national boundaries and capabilities, as well as the lack of national will to commit resources abroad. The common perception is that military engagements are costly, enduring, and incite division amongst constituents. With regard to the large footprint that general purpose forces generally require, these perceptions often mirror reality. Nonetheless, avoidance is not an option. Therefore, in order to combat transnational insecurity and violence, a collective, global solution is required.

\section{Special Operations as the Global Solution}

Special Operations Forces (SOF) by nature of their agile, unobtrusive and costeffective profile represents the ideal force to lead such a response. More specifically, by empowering partners to develop local solutions to global problems, SOF networks provide a collective, often preemptive, and cost-effective security solution for an increasingly volatile and interconnected world. Specifically, as part of a whole-of-government approach, SOF employ special and unique operational methodologies in hostile, denied or politically sensitive areas to achieve desired effects in times of peace, conflict or war.

In order to achieve these desired effects, SOF are specially selected, trained and equipped for these special missions. Of particular relevance is the caliber of the individual who is selected to serve in a SOF organization as these personnel are what create the SOF advantage. Specifically, SOF organizations seek individuals who accept risk, think creatively, act with agility, adapt, and are self-reliant, eager for challenge, relentless in their pursuit of mission success and culturally attuned. This selection, combined with specialized training and education, enable SOF to behave in a culturally intelligent manner, which is paramount in building effective networks among international SOF partners.

In essence, SOF networks leverage the best strengths of the contributing partner nations in terms of resources, cultural knowledge and language ability, as well as geographic positioning. They increase interoperability by helping to build personal trust and relationships, as well as providing the opportunity for outreach, and the sharing of knowledge and resources through collective training and education. Additionally, there is the possibility of establishing forward operating bases that can act as both a deterrent and advanced staging area should the belligerence escalate. Perhaps most important, however, the increased training and education afforded to local SOF can enable them to be able to conduct operations on their own. As such, one of the biggest benefits that SOF networks furnish is the possibility for a rapidly deployable local SOF to deal with 
a local problem that has the potential of escalating into a global concern if it is not dealt with swiftly and decisively.

\section{Cultural Intelligence}

To work effectively in this global environment, SOF behaves in a culturally intelligent manner. Cultural intelligence-or cross cultural competence or cultural savvy as some have referred to it- refers to the ability to recognize the shared beliefs, values, attitudes and behaviors of a group of people and, most importantly, to apply this knowledge toward a specific goal. ${ }^{1}$ More specifically, cultural intelligence refers to the cognitive, motivational and behavioral capacities to understand and effectively respond to the beliefs, values, attitudes and behaviors of members of your own and other groups, societies and cultures under complex and changing circumstances in order to affect a desired change. It is about understanding the message that is being sent, making sure that the intent of your message is being properly understood and, ultimately, influencing a target group of people to achieve your goal. ${ }^{2}$

Importantly, cultural intelligence is more than just cultural awareness. You can think of this relationship in terms of building a puzzle. Cultural awareness represents the pieces of the puzzle-the information about people and places, the "dos" and "don'ts." Cultural intelligence in this case is the "big picture" that allows you to put these pieces together in order to build your plan and achieve your goal. Putting together a thousand piece puzzle without any concept of what it is supposed to look like would be a real challenge; equally as demanding is putting together a puzzle without having all the pieces. Clearly, cultural intelligence and cultural awareness go hand-in-hand.

First and foremost though, that big picture view-cultural intelligence-is what allows SOF to work effectively with people from a variety of cultural backgrounds, sometimes with little advanced notice regarding deployments. From a cognitive perspective, the principal elements required to behave in a culturally intelligent manner are a basic understanding of what culture is and how it affects people's worldviews, and the ability to think critically and creatively, elements that are sometimes grouped under the umbrella concept of strategic thinking. ${ }^{3}$

While there is still a lack of consensus as to the exact definition of culture, in basic terms, it can be defined as a common set of beliefs and values within a group of people that combined transform into attitudes and get expressed as

\footnotetext{
${ }^{1}$ There are several different terminologies used to express the advantageous use of cultural knowledge. These terms include, but are not limited to, cultural savvy, cultural astuteness, cultural literacy, cultural appreciation, cultural expertise, human terrain, cultural awareness, cultural competency, and cross-cultural competence. There are also many different proposed acronyms for cultural intelligence, for example, CI, CULTINT, and CQ.

${ }^{2}$ For a review of a summary of some contemporary views on the cultural intelligence within the business world, as well as Western militaries see: Spencer, Emily, Solving the People Puzzle: Cultural Intelligence and Special Operations Forces (Toronto: Dundurn Press, 2010), Chapter 5. 3 While cognitive skills are but one element of demonstrating cultural intelligence, the psychological dimension to demonstrating high levels of cultural intelligence as well as the motivational element to do so will not be discussed further. Selection helps to address these issues within the SOF community and further education and/or awareness in these areas can enhance these elements as well.
} 
behaviors. ${ }^{4}$ Clearly, culture helps create both individual and group identity. More importantly, individual and group identities also help to define culture.

Culture provides the meaning to how we see the world and our place in it, what we see as important, and how we think and act. Notably, meaning is almost always culturally derived and, as such, culture can be seen as being about sensemaking. It is about creating understandings and connections, and interpreting the world around us. 5

While culture to a degree is derived by geographic and geopolitical "realities," (e.g. it is a response to the physical world in which we live), it is important to recognize that cultures are social constructs and therefore subject to change. Interestingly, culture is often seen as being so imbedded within a group of people that it is immutable. Conversely though, the opposite is true. Culture is in a constant state of flux and change, negotiation and renegotiation. Notably, however, the beliefs, values and attitudes associated with a specific culture are often passed down through generations and are generally subconscious in nature.

While there are myriad outside factors that may influence behaviour, it is the cultural meaning associated with these factors that influences the behaviour. As such, it is essential to understand the "currency" that motivates the group of people with whom you are working. In order to do so, you need to appreciate the beliefs, values and attitudes of the group of people with whom you are interacting. For instance, an American business owner on Saipan, a U.S. Protectorate in the Northern Marianna Islands, once complained that every time she gave the locals who worked at her shop a raise to reward their good service, they would simply cut back their work hours. From their perspective, they could now earn a living working fewer hours a week. The American woman, however, could not understand their lack of motivation to earn more money than simply that required for survival. But for the Chamorro people native to the Marianna Islands, leisure was valued over money. They believed free time was more valuable than accumulating financial wealth. As a result, the American was hard

4 English, Allan D., Understanding Military Culture: A Canadian Perspective (Montreal: McGillQueen's University Press, 2004), 12; notably, there is long-standing debate about the nature and definition of culture. The 2006 American counter-insurgency manual, for example, contrasts cultural and social structures. It explains: "Social structure comprises the relationships among groups, institutions, and individuals within a society; in contrast, culture (ideas, norms, rituals, codes of behavior) provide meaning to individuals within the society." It defines culture as a "web of meaning' shared by members of a particular society or group within a society." The manual explains this definition in terms of people's identity, beliefs, values, attitudes, perceptions and belief systems. It also emphasizes that cultural knowledge about insurgents, as far as the military is concerned, should be exploited to be used to further U.S. national objectives; U.S. Department of the Army, 3-24 Counterinsurgency (Washington, D.C.: HQDA, 2006): 3-6, 3-8; Similarly, scholar Adam Bozeman defines culture as "Those norms, values, institutions and modes of thinking in a given society that survive change and remain meaningful to successive generations"; Adda Bozeman, cited in Montgomery McFate, "The Military Utility of Understanding Adversary Culture," Joint Force Quarterly 38 (2005): 48, note 4; While all these definitions (as well as most of the available definitions of culture) are complementary, English's does an exceptional job of breaking culture down into its component parts and thereby making the concept of culture more understandable at a structural level.

5 Notably, individuals may be part of many cultural groupings at once. Those that are considered sub-sets of a larger cultural grouping yet complement each other are considered to be subcultures. Those that exist as sub-sets of a larger culture but whose beliefs and values contradict and try to erode those of the larger cultural group are considered counter-cultures. This paper does not provide a detailed discussion of sub-cultures or counter-cultures. 
pressed to find an effective means of rewarding her employees and also still have people to work at her store. She first needed to understand their cultural perspective in order to be able to influence them. ${ }^{6}$

\section{Culture and the Afghan Experience}

Additionally, it is helpful to appreciate the role of perceptions. Seeing the world through someone else's eyes can often times be a difficult task in self-reflection, but it can also help to ensure that messages are not "lost in translation." For example, one Canadian Armed Forces (CAF) member recalled training a group of Afghans and stressing the importance of having vehicle check-points. In fact, the Afghans saw how often the Canadians and Americans performed these checks so it was not difficult to gain their "buy-in." The Afghans subsequently stopped cars repeatedly but they never actually searched any of them, as that is all that they had observed the Canadians and Americans doing. While they understood the "action," they had no idea why it was being done so they simply mimicked the superficial behaviors that they had witnessed. It was not until the rationale for road checks was explained and their importance was underscored that the Afghans began to behave effectively.7

Indeed, a delta between the intended message and that which is received can create a multitude of problems. For instance, during the recent war in Afghanistan (c. 2001-2013) a CAF member mentioned that Afghans were getting very frustrated when their dogs were being shot on night raids. The dogs were being killed because they would bark and thereby potentially alert the Taliban to the location of the coalition forces. Having their dogs shot was clearly aggravating the locals and, in fact, an elderly Afghan man approached the CAF member after a night raid and said he would rather they shot one of his children instead of his dog. The CAF member was stunned. In his perception, if this was how the Afghans felt about their families, particularly their children, then he began to question the whole rationale for a Canadian presence in the country.

Certainly, taking what the Afghan said at face-value contradicted everything the CAF member thought he knew about the local population. The mere idea that the Afghan preferred his dog to his children is shocking considering how Afghans treated their dogs: In Afghanistan, for the most part, dogs are working animals, not pets. Notably, however, not only are they working animals, but a well-trained dog is rare, expensive and often vital for safety and survival. Additionally, based on this encounter, the Afghan had failed to demonstrate any real emotion with regard to his family, which seemed surprising given that family, clan, and tribe are by all accounts important to their culture, at least from a Western perception. Indeed, from everything Westerners think they know about Afghans, family is important to them.

By taking this knowledge into account when interpreting the Afghan's comments, a different interpretation presents itself. "Kill one of my children rather than my dog" might mean just that or it could mean, "If you kill my dog, you are severely limiting my ability to take care of my whole family and as such it is preferable to

${ }^{6}$ Conversation with the author while living on Saipan in 1998.

7 Interview with the author, November 2012. 
kill just one of my children rather than my whole family." The Afghan may not have been valuing his dog's life over that of his child's in direct terms as it first appeared. Rather, he may have been thinking about how best he could take care of his whole family and trying to express the gravity of the situation to the Westerners-perhaps in language that he thought they would understand.

When interpreted in this manner, the reaction to the statement is different. Instead of disgust, the gravity of the situation is underscored and the motivation to find an alternate solution to killing dogs that bark on night raids increase.

This example underscores the second key cognitive element involved in behaving in a culturally intelligent manner: The ability to think strategically. Thinking is a process that we do every day and, like breathing, we are sometimes conscious of it and more often than not we take it for granted. Often when one behaves in a careless or inappropriate way, the reasoning, or more appropriately the excuse, is that you were "not thinking." The reality is, however, that you were thinking, you simply were not doing so effectively. Like an elite athlete who learns to control his or her breathing in order to maximize output, one's ability to think more effectively can be practiced and improved upon.

\section{Critical and Creative Thinking}

The term "Strategic Thinking" has surfaced in the military-academic literature in order to identify the ways in which commanders should make decisions. It combines elements of critical and creative thinking in order to help commanders determine the best course of action. Certainly it is beneficial to combine the convergent thought process of critical thinking which helps you determine the core beliefs and values that are at issue with the divergent thought process of creative thinking which, once having identified core beliefs and values at play, encourages you to "think outside of the box" in order to find novel, often simple, solutions. In fact, within a defense paradigm, you cannot really effectively apply creative thinking skills until you have applied critical thinking skills and identified the real root of the problem / issue. As such, it makes sense that strategic thinking incorporates these two thought processes.

Another inextricable element in the thought process, however, is emotional thinking. While many military practitioners may shy away from a discussion of emotions, it is important to note that, as humans, little we do is devoid of emotion. Fear, fatigue and stress do affect how we think and the decisions that we make. So do time constraints, which often increase the emotional intensity of an issue and which are certainly pervasive within the contemporary operating environment. As such, emotional thinking will likely always be a factor.

Understanding the general concepts of critical and creative thinking, engaging in professional development activities that encourage the improvement of these skills, and continuously being aware that emotional thinking will always be part of the equation help SOF demonstrate high levels of cultural intelligence when deployed. More importantly, strategic thinking is vital in determining the intent of the message, what information is accurate and relevant, and what questions still remain. 
Appreciating cultural perspectives combined with the ability to engage in strategic thinking, enables the expression of cultural intelligence. Failure to apply high levels of cultural intelligence can have grave consequences. For example, throughout the counter-insurgency operation in Afghanistan, Americans were detaining certain individuals and questioning them. In the case of Afghan teenage boys, which represented a high target group since many of the insurgents in Afghanistan are young males, an Afghan elder warned coalition members that these boys needed to be "home by a certain time." The Americans understood what "home by a certain time" meant, specifically before dark, but they did not pay much attention to the comment. While questioning could last for hours, and often only ended in the middle of the night, the Afghans were always offered a ride home-which apparently few, if any, ever took-so the Americans thought they had done their due diligence. What the Americans did not understand, however, was that in Afghanistan, while the rape of young boys is not uncommon, if a boy is suspected of having been molested, he could lose all social status and be disowned by his family. Returning home after dark, with no one to account for their whereabouts during their absence, many of the young men who had been detained could end up being shunned by their families. With few places to turn, joining the insurgency could seem like a good, if not solitary, option. Notably, it took a decade before the significance of their actions was fully understood. The Americans had made a conscious effort to minimize the number of insurgents in Afghanistan but, in this case, they lacked the knowledge, or possibly motivation, to recognize the significance of what the Afghan elder was telling them. ${ }^{8}$

Additionally, it is important to note that cultural intelligence should not simply be applied when dealing with a culture that is considered "foreign" or antagonistic. Cultural intelligence helps you work more effectively with people from your own culture, including different subcultures, people with whom you interact with in a friendly manner, people with whom you interact strictly for business purposes and also the group that is actively working against what you want to achieve. In short, cultural intelligence can be beneficial when dealing with human interaction at any group level.

More precisely, within the context of defense, cultural intelligence needs to be applied in the context of the national, international, host nation, and enemy domains in order to be most effectively utilized. Western militaries need to understand and work effectively within the contexts of their own national cultures (home domain). They also need to work well within coalitions (international domain). Moreover, when deployed, it is essential to function effectively with local populations (host nation domain). Finally, cultural intelligence can also help with the ability to identify, target and influence members within the enemy domain. Notably, action in any one of these domains can-and probably will-affect the others and each domain is dynamic in its own right. 9

Further complicating this issue is the pervasiveness of the media and social media. Something that may be seen as acceptable within the context in which it

\footnotetext{
${ }^{8}$ David C. Ellis, “'Home by a Certain Time’: Ontology We do Not Know but Must” draft paper distributed to the author.

9 For a more detailed account of the Four Domains see Spencer, Solving the People Puzzle, 87-102.
} 
is being acted-out has a high probability of being circulated much more widely than anticipated and/or desired. Particularly for people in the public domain or people who serve in a public role such as military members, behaviors need to be above reproach when viewed in any cultural context at any time. While this fact might be easy to state and acknowledge, as life has demonstrated, it is not necessarily easy to do. One need only think back to the 2011 video of U.S. Marines urinating on the bodies of dead Taliban for just one vivid portrayal of the consequences of military members not applying cultural intelligence when deployed. ${ }^{10}$

Applying enhanced cultural intelligence in all four domains can help to minimize negative outcomes and maximize positive ones. Specifically, within all four domains, cultural intelligence helps you understand the groups you are working with and amongst. This information is important because it provides insight into what beliefs, values and attitudes are driving behaviors which can help you: Identify which people belong to which groups; be able to assess what information is relevant and accurate and, importantly, what questions still remain; predict behavior; and, ultimately, influence behavior to your desired end state. In essence, whether at home, working with allies, working in a foreign country or actively engaged in a conflict, cultural intelligence can help you understand, predict and influence the behaviors of others in order to achieve your desired results.

Notably, neither the concept of allies and partnered nations working together for a common purpose, nor the concept of cultural intelligence is new. Arguably, they can each trace their lineage to the first conflicts and wars. What the 21st Century concept of global SOF networks is doing is taking an old, almost common sense idea and applying it to the contemporary operating environment in hopes of shaping the future operating environment in a desirable manner. By forging relationships before a crisis, SOF networks are about maximizing the benefits of SOF-their agility, small footprint and cost effectiveness, just to mention a few-through one of their principle characteristics, precisely their aptitude and ability to perform in a culturally intelligent manner.

\section{Conclusion}

Indeed, the strength of SOF networks resides in the personal relationships that are forged between members of partnered forces, and which transcend and build trust between partnered nation forces at large. Cultural intelligence is a key enabler in this process. As the examples throughout this article have demonstrated, it is easy to determine when cultural intelligence has not been applied. In relationships that progress smoothly, however, even if it is difficult to measure, enhanced cultural intelligence is surely at play.

\footnotetext{
10 The video was shot in 2011 and ended up being widely circulated on the Internet in early 2012. In January 2013 one of the U.S. Marines who was on trial for this act pled guilty. He stated that "he knew desecrating the corpses and posing for the 'trophy photographs' was wrong and he offered no excuse for the behavior during his court martial." Additionally, he stated, "I was in a position to stop it and I did not"; Judy Royal, "Marine pleads guilty to urinating on bodies of dead Taliban, posing for Photographs," NBCNews.com, January 16, 2013, available at: http://usnews.nbcnews.com/_news/2013/o1/16/16552152-marine-pleads-guilty-to-urinatingon-bodies-of-dead-taliban-posing-for-photographs?lite.
} 
Ultimately, strengthening SOF networks provides a collective solution to counter worldwide threats and does so by enabling a local solution to a global problem. Through resource sharing and dynamic cooperation, global SOF networks allow nations to have a more responsive, nimble and effective impact at less individual cost. As such, they are not just a viable solution to an ever growing complex and dangerous international security environment; rather, they are a fast, resourceful and sustainable solution. Notably, having enhanced cultural intelligence within SOF personnel will be paramount to the success of global SOF networks. 